\author{
B.Sh. Kulpeshov ${ }^{1}$, S.V. Sudoplatov ${ }^{2,3}$ \\ ${ }^{1}$ International Information Technologies University, Almaty, Kazakhstan; \\ ${ }^{2}$ S.L. Sobolev Institute of Mathematics, Novosibirsk State Technical University, Russia; \\ ${ }^{3}$ Novosibirsk State University, Russia \\ (E-mail: b.kulpeshov@iitu.kz, sudoplat@math.nsc.ru)
}

\title{
On structures in hypergraphs of models of a theory
}

\begin{abstract}
Hypergraphs of models of a theory are derived objects allowing toobtain an essential structural information about both giventheories and related semantic objects including graph ones. In the present paper we define and study structural properties of hypergraphs of modelsof a theory including lattice ones. Characterizations for thelattice properties of hypergraphs of models of a theory, as wellas for structures on sets of isomorphism types of models of atheory, are given.
\end{abstract}

Keywords: hypergraph of models, elementary theory, elementarily substructural set, lattice structure.

Hypergraphs of models of a theory are derived objects allowing to obtain an essential structural information about both given theories and related semantic objects including graph ones [1-9]. Studying of hypergraphs of models of a theory is closely related with a series of papers on description of lattices of substructures [10-22].

In the presented paper we define and study structural properties of hypergraphs of models of a theory including lattice ones. Characterizations for the lattice properties of hypergraphs of models of a theory as well as for structures on sets of isomorphism types of models of a theory are given.

\section{Preliminaries}

Recall that a hypergraph is a pair of sets $(X, Y)$, where $Y$ is some subset of the Boolean $\mathcal{P}(X)$ of the set $X$.

Let $\mathcal{M}$ be some model of a complete theory $T$. Following [5], we denote by $H(\mathcal{M})$ a family of all subsets $N$ of the universe $M$ of $\mathcal{M}$ that are universes of elementary submodels $\mathcal{N}$ of the model $\mathcal{M}: H(\mathcal{M})=\{N \mid \mathcal{N} \preccurlyeq \mathcal{M}\}$. The pair $(M, H(\mathcal{M}))$ is called the hypergraph of elementary submodels of the model $\mathcal{M}$ and denoted by $\mathcal{H}(\mathcal{M})$.

Definition [8]. Let $\mathcal{M}$ be a model of a theory $T$ with a hypergraph $\mathcal{H}=(M, H(\mathcal{M})$ ) of elementary submodels, $A$ be an infinite definable set in $\mathcal{M}$, of arity $n: A \subseteq M^{n}$. The set $A$ is called $\mathcal{H}$-free if for any infinite set $A^{\prime} \subseteq A$, $A^{\prime}=A \cap Z^{n}$ for some $Z \in H(\mathcal{M})$ containing parameters for $A$. Two $\mathcal{H}$-free sets $A$ and $B$ of arities $m$ and $n$ respectively are called $\mathcal{H}$-independent if for any infinite $A^{\prime} \subseteq A$ and $B^{\prime} \subseteq B$ there is $Z \in H(\mathcal{M})$ containing parameters for $A$ and $B$ and such that $A^{\prime}=A \cap Z^{m}$ and $B^{\prime}=B \cap Z^{n}$.

Note the following properties [8].

1. Any two tuples of a $\mathcal{H}$-free set $A$, whose distinct tuples do not have common coordinates, have same type.

Indeed, if there are tuples $\bar{a}, \bar{b} \in A$ with $\operatorname{tp}(\bar{a}) \neq \operatorname{tp}(\bar{b})$ then for some formula $\varphi(\bar{x})$ the sets of solutions of that formula and of the formula $\neg \varphi(\bar{x})$ divide the set $A$ into two nonempty parts $A_{1}$ and $A_{2}$, where at least one part, say $A_{1}$, is infinite. Taking $A_{1}$ for $A^{\prime}$ we have $A_{1}=A \cap Z^{n}$ for appropriate $Z \in H(\mathcal{M})$ and $n$. Then by the condition for tuples in $A$ we have $A_{2} \cap Z^{n}=\emptyset$ that is impossible since $Z$ is the universe of an elementary submodel of $\mathcal{M}$.

Thus the formula $\varphi(\bar{x})$, defining $A$, implies some complete type in $S^{n}(\emptyset)$, and if $A$ is $\emptyset$-definable then $\varphi(\bar{x})$ is a principal formula.

In particular, if the set $A$ is $\mathcal{H}$-free and $A \subseteq M$, then the formula, defining $A$, implies some complete type in $S^{1}(\emptyset)$.

2. If $A \subseteq M$ is a $\mathcal{H}$-free set, then $A$ does not have nontrivial definable subsets, with parameters in $A$, i.e., subsets distinct to subsets defined by equalities and inequalities with elements in $A$.

Indeed, if $B \subset A$ is a nontrivial definable subset then $B$ is defined by a tuple $\bar{a}$ of parameters in $A$, forming a finite set $A_{0} \subset A$, and $B$ is distinct to subsets of $A_{0}$ and to $A \backslash C$, where $C \subseteq A_{0}$. Then removing from $A$ a set $B \backslash A_{0}$ or $(A \backslash B) \backslash A_{0}$, we obtain some $Z \in H(\mathcal{M})$ violating the satisfiability for $B$ or its complement. It contradicts the condition that $Z$ is the universe of an elementary submode of $\mathcal{M}$.

3. If $A$ and $B$ are two $\mathcal{H}$-independent sets, where $A \cup B$ does not have distinct tuples with common coordinates, then $A \cap B=\emptyset$. 
Indeed, if $A \cap B$ contains a tuple $\bar{a}$, then, choosing infinite sets $A^{\prime} \subseteq A$ and $B^{\prime} \subseteq B$ with $\bar{a} \in A^{\prime}$ and $\bar{a} \notin B^{\prime}$, we obtain $\bar{a} \in A^{\prime}=A \cap Z^{n}$ for appropriate $Z \in H(\mathcal{M})$ and $n$, as so $\bar{a} \in B \cap Z^{n}=B^{\prime}$. This contradiction means that $A \cap B=\emptyset$.

Definition [6]. The complete union of hypergraphs $\left(X_{i}, Y_{i}\right), i \in I$, is the hypergraph $\left(\bigcup_{i \in I} X_{i}, Y\right)$, where $Y=\left\{\bigcup_{i \in I} Z_{i} \mid Z_{i} \in Y_{i}\right\}$. If the sets $X_{i}$ are disjoint, the complete union is called disjoint too. If the set $X_{i}$ form a $\subseteq$-chain, then the complete union is called chain.

By Property 3 we have the following theorem on decomposition of restrictions of hypergraphs $\mathcal{H}$, representable by unions of families of $\mathcal{H}$-independent sets.

Theorem $1.1[8]$. A restriction of hypergraph $\mathcal{H}=(M, H(\mathcal{M}))$ to a union of a family of $\mathcal{H}$-free $\mathcal{H}$-independent sets $A_{i} \subseteq M$ is represented as a disjoint complete union of restrictions $\mathcal{H}_{i}$ of the hypergraph $\mathcal{H}$ to the sets $A_{i}$.

Proof. Consider a family of $\mathcal{H}$-independent sets $A_{i} \subseteq M$. By Property 3 these sets are disjoint, and using the definition of $\mathcal{H}$-independence we immediately obtain that the union of restrictions $\mathcal{H}_{i}$ of $\mathcal{H}$ to the sets $A_{i}$ is complete.

Recall that a subset $A$ of a linearly ordered structure $M$ is called convex if for any $a, b \in A$ and $c \in M$ whenever $a<c<b$ we have $c \in A$. A weakly o-minimal structure is a linearly ordered structure $M=\langle M,=,<, \ldots\rangle$ such that any definable (with parameters) subset of the structure $M$ is a union of finitely many convex sets in $M$.

In the following definitions $M$ is a weakly o-minimal structure, $A, B \subseteq M, M$ be $|A|^{+}$-saturated, $p, q \in S_{1}(A)$ be non-algebraic types.

Definition. [23]. We say that $p$ is not weakly orthogonal to $q\left(p \not \not^{w} q\right)$ if there exist an $A$-definable formula $H(x, y), \alpha \in p(M)$ and $\beta_{1}, \beta_{2} \in q(M)$ such that $\beta_{1} \in H(M, \alpha)$ and $\beta_{2} \notin H(M, \alpha)$.

Definition. [24]. We say that $p$ is not quite orthogonal to $q\left(p \not \not^{q} q\right)$ if there exists an $A$-definable bijection $f: p(M) \rightarrow q(M)$. We say that a weakly o-minimal theory is quite o-minimal if the notions of weak and quite orthogonality of 1-types coincide.

In the work [25] the countable spectrum for quite o-minimal theories with non-maximal number of countable models has been described:

Theorem 1.2. Let $T$ be a quite o-minimal theory with non-maximal number of countable models. Then $T$ has exactly $3^{k} \cdot 6^{s}$ countable models, where $k$ and $s$ are natural numbers. Moreover, for any $k, s \in \omega$ there exists a quite o-minimal theory $T$ having exactly $3^{k} \cdot 6^{s}$ countable models.

Realizations of these theories with a finite number of countable models are natural generalizations of Ehrenfeucht examples obtained by expansions of dense linear orderings by a countable set of constants, and they are called theories of Ehrenfeucht type. Moreover, these realizations are representative examples for hypergraphs of prime models $[1,3,5]$. We consider operators for hypergraphs allowing on one hand to describe the decomposition of hypergraphs of prime models for quite o-minimal theories with few countable models, and on the other hand pointing out constructions leading to the building of required hypergraphs by some simplest ones.

Having nontrivial structures like structures with some orders it is assumed that «complete» decompositions are considered modulo additional conditions guaranteing the elementarity for substructures with considered universes. So we use the conditional completeness taking unions with the properties of density, linearity etc.

Below we illustrate this conditional completeness for structures with dense linear orders.

Denote by $\left(M, H_{\mathrm{dlo}}(\mathcal{M})\right)$ the hypergraph of (prime) elementary submodels of a countable model $\mathcal{M}$ of the theory of dense linear order without endpoints.

Remark 1.3. The class of hypergraphs $\left(M, H_{\mathrm{dlo}}(\mathcal{M})\right)$ is closed under countable chain complete unions, modulo density and having an encompassing dense linear order without endpoints. Thus, any hypergraph $\left(M, H_{\mathrm{dlo}}(\mathcal{M})\right)$ is represented as a countable chain complete, modulo density, union of some its proper subhypergraphs. The notion of weak o-minimality was originally studied by D. Machpherson, D. Marker and C. Steinhorn in $[26]$.

Any countable model of a theory of Ehrenfeucht type is a disjoint union of some intervals, which are ordered both themselves and between them, and of some singletons. Dense subsets of the intervals form universes of elementary substructures. So, in view of Remark 1.3, we have:

Theorem 1.4 [6]. A hypergraph of prime models of a countable model of a theory of Ehrenfeucht type is represented as a disjoint complete, modulo density, union of some hypergraphs in the form $\left(M, H_{\mathrm{dlo}}(\mathcal{M})\right)$ as well as singleton hypergraphs of the form $(\{c\},\{\{c\}\})$. 
Remark 1.5. Taking into consideration links between sets of realizations of 1-types, which are not weakly orthogonal, as well as definable equivalence relations, the construction for the proof of Theorem 1.4 admits a natural generalization for an arbitrary quite o-minimal theory with few countable models. Here conditional complete unions should be additionally coordinated, i.e., considering definable bijections between sets of realizations of 1-types, which are not quite orthogonal.

\section{Elementarily substructural sets}

Let $\mathcal{M}$ be a model of theory $T,(M, H(\mathcal{M}))$ be a hypergraph of elementary submodels of $\mathcal{M}$. The sets $N \in H(\mathcal{M})$ are called elementarily submodel or elementarily substructural in $\mathcal{M}$.

Elementarily substructural sets in $\mathcal{M}$ are characterized by the following well-known Tarski-Vaught Theorem, which is called the Tarski-Vaught test.

Theorem 2.1. Let $\mathcal{A}$ and $\mathcal{B}$ be structures in a language $\Sigma, \mathcal{A} \subseteq \mathcal{B}$. The following are equivalent:

(1) $\mathcal{A} \preccurlyeq \mathcal{B}$

(2) for any formula $\varphi\left(x_{0}, x_{1}, \ldots, x_{n}\right)$ in the language $\Sigma$ and for any elements $a_{1}, \ldots, a_{n} \in A$, if $\mathcal{B}=\exists x_{0} \varphi\left(x_{0}, a_{1}, \ldots, a_{n}\right)$ then there is an element $a_{0} \in A$ such that $\mathcal{B}=\varphi\left(a_{0}, a_{1}, \ldots, a_{n}\right)$.

Corollary 2.2. A set $N \subseteq M$ is elementarily substructural in $\mathcal{M}$ if and only if for any formula $\varphi\left(x_{0}, x_{1}, \ldots, x_{n}\right)$ in the language $\Sigma(\mathcal{M})$ and for any elements $a_{1}, \ldots, a_{n} \in N$, if $\mathcal{M} \models \exists x_{0} \varphi\left(x_{0}, a_{1}, \ldots, a_{n}\right)$ then there is an element $a_{0} \in N$ such that $\mathcal{M} \models \varphi\left(a_{0}, a_{1}, \ldots, a_{n}\right)$.

Proposition 2.3. Let $A$ be a definable set in an $\omega_{1}$-saturated model $\mathcal{M}$ of a countable complete theory $T$. Then exactly one of the following conditions is satisfied:

(1) $A$ is finite and contained in any elementarily substructural set in $\mathcal{M}$;

(2) $A$ is infinite and has infinitely many distinct intersections with elementarily substructural sets in $\mathcal{M}$, and all these intersections are infinite; these intersections can be chosen forming an infinite chain/antichain by inclusion.

Proof. If $|A|<\omega$ then $A$ is contained in $\operatorname{acl}(\emptyset)$, and so it is contained in any elementary submodel of $\mathcal{M}$.

If $A=\varphi(\mathcal{M}, \bar{a})$ is infinite, we construct a countable submodel $\mathcal{N}_{0} \prec \mathcal{M}$ containing parameters in $\bar{a}$. Since $A$ is infinite, the set $A \cap N_{0}$ is countable. By compactness, since $\mathcal{M}$ is $\omega_{1}$-saturated, the set $A \backslash N_{0}$ is infinite. Adding to $N_{0}$ new elements of $A$ we construct a countable model $\mathcal{N}_{1}$ such that $\mathcal{N}_{0} \prec \mathcal{N}_{1} \prec \mathcal{M}$. Continuing the process we build an elementary chain of models $\mathcal{N}_{k}, k \in \omega$, such that $\mathcal{N}_{k} \prec \mathcal{M}$ and $A \cap N_{k} \subset A \cap N_{k+1}, k \in \omega$.

Constructing the required antichain of intersections $A \cap N$ with elementarily substructural sets $N$, it suffices to use [9, Theorem 2.10] allowing to separate disjoint finite sets, whose elements do not belong to acl $(\emptyset)$.

The arguments for the proof of Proposition 2.3 stay valid for a countable saturated model $\mathcal{M}$. Thus, we have the following

Proposition 2.4. Let $A$ be a definable set in a countable saturated model $\mathcal{M}$ of a small theory $T$. Then exactly one of the following conditions is satisfied:

(1) $A$ is finite and contained in any elementarily substructural set in $\mathcal{M}$;

(2) $A$ is infinite and has infinitely many distinct intersections with elementarily substructural sets in $\mathcal{M}$, and all these intersections are infinite; these intersections can be chosen forming an infinite chain/antichain by inclusion.

The following example illustrates that if $\mathcal{M}$ is not saturated then the conclusions of assertions 2.3 and 2.4 can fail.

Example 2.5. Let a set $A$ is defined by a unary predicate $P$ and includes infinitely many language constants $c_{i}, i \in I$. Then there is, in the language $\{P\} \cup\left\{c_{i} \mid i \in I\right\}$, a structure $\mathcal{M}$ having only finite set $A_{0}$ of elements in $A$, which are not interpreted by constants. Since elementarily substructural sets $N$ take all constants, there are only finitely many possibilities for intersections $A \cap N$.

In view of aforesaid arguments it is interesting to describe possible cardinalities both for sets $H(\mathcal{M})$ and their restrictions $H(\mathcal{M}) \uparrow A \rightleftharpoons\{A \cap N \mid N \in H(\mathcal{M})\}$ on definable sets $A \subseteq M$.

Since in Example 2.5 intersections $A \cap N$, taking all constants $c_{i}$, can include an arbitrary subset of $A_{0}$, then for this example we have $\mid H(\mathcal{M})\left\lceil A \mid=2^{\left|A_{0}\right|}\right.$. The same formula holds for infinite sets $A_{0}$, but in such a case the set $H(\mathcal{M})\lceil A$ is transformed from finite one directly to a set with continuum many elements.

Note that for $\mathcal{H}$-free sets $A \subseteq M$, modulo $\operatorname{acl}(\emptyset)$ (i.e., for sets $A$, whose each subset $B \subseteq A \backslash$ acl $(\emptyset)$ has a representation $B \cup(\operatorname{acl}(\emptyset) \cap A)=A \cap N$ for some $N \in H(\mathcal{M}))$, the equality $|H(\mathcal{M}) \uparrow A|=2^{\mid A \backslash \text { acl }(\emptyset) \mid}$ holds. Thus, we have the following dichotomy theorem.

Theorem 2.6. For any $\mathcal{H}$-free, modulo acl $(\emptyset)$, set $A \subseteq M$ its restriction to any elementary submodel $\mathcal{M}_{0} \prec \mathcal{M}$ satisfies either $\mid H\left(\mathcal{M}_{0}\right)\left\lceil A \mid=2^{n}\right.$ for some $n \in \omega$, or $\left|H\left(\mathcal{M}_{0}\right) \uparrow A\right|=2^{\lambda}$ form some $\lambda \geq \omega$. 
Similar to Example 2.5, the following example illustrates the dichotomy for hypergraphs of elementary submodels.

Example 2.7. Consider the structure $\mathcal{M}$ of rational numbers, $\left\langle\mathbf{Q},<, c_{q}\right\rangle_{q \in \mathbf{Q}}$, in which every element is interpreted by a constant. This structure does not have proper elementary substructures, therefore $|H(\mathcal{M})|=1=2^{0}$. Extending $\mathcal{M}$ to a structure $\mathcal{M}_{1}$ by addition of $n$ elements for pairwise distinct 1-types, defined by cuts, we have $\left|H\left(\mathcal{M}_{1}\right)\right|=2^{n}$. If $\mathcal{M}$ is extended till a structure $\mathcal{M}_{2}$ by addition of at least two elements of fixed cut or of infinitely many elements for distinct cuts, then by density the summarized number of added elements occurs infinite and $\left|H\left(\mathcal{M}_{2}\right)\right|=2^{\lambda}$ holds for some $\lambda \geq \omega$.

At the same time there are examples of hypergraphs of elementary submodels, for which the conclusion of Theorem 2.6 fails. For instance, as shown in [13], there are hypergraphs for the theory of arithmetic of natural numbers such that $|H(\mathcal{M})|=5$ and the lattice of elementary submodels is isomorphic to the lattice $P_{5}$.

\section{Lattice structures associated with hypergraphs of models of a theory}

For given structure $\mathcal{M}$ we define the structure $L(\mathcal{M})=\langle H(\mathcal{M}) ; \wedge, \vee\rangle$ by the following relations for $\mathcal{M}_{1}, \mathcal{M}_{2} \prec \mathcal{M}: \mathcal{M}_{1} \wedge \mathcal{M}_{2}=\mathcal{M}_{1} \cap \mathcal{M}_{2}$ and $\mathcal{M}_{1} \vee \mathcal{M}_{2}=\mathcal{M}\left(M_{1} \cup M_{2}\right)$.

Consider the following question: when the structure $L(\mathcal{M})$ is a lattice?

Clearly, answering this question we have to characterize the conditions $\mathcal{M}_{1} \cap \mathcal{M}_{2} \prec \mathcal{M}$ and $\mathcal{M}\left(M_{1} \cup M_{2}\right) \prec \mathcal{M}$. Assuming that $\mathcal{M}$ is infinite, the structures $\mathcal{M}_{1} \cap \mathcal{M}_{2}$ should be infinite too, in particular, $M_{1} \cap M_{2} \neq \emptyset$. By [5, Theorem 3.2], assuming that $\mathcal{M}$ is $\lambda$-saturated, it can not contain separated sets $A$ and $B$ of cardinalities $<\lambda$, such that $\operatorname{acl}(A) \cap \operatorname{acl}(B)=\emptyset$.

By Theorem 2.1 we have the following theorems characterizing the elementarity of substructures.

Theorem 3.1. Let $\mathcal{M}_{1}$ and $\mathcal{M}_{2}$ be elementary substructures of structure $\mathcal{M}$ in a language $\Sigma, M_{1} \cap M_{2} \neq \emptyset$. The following are equivalent:

(1) $\left(\mathcal{M}_{1} \cap \mathcal{M}_{2}\right) \prec \mathcal{M}$;

(2) for any formula $\varphi\left(x_{0}, x_{1}, \ldots, x_{n}\right)$ of the language $\Sigma$ and for any elements $a_{1}, \ldots, a_{n} \in M_{1} \cap M_{2}$ if $\mathcal{M} \models \exists x_{0} \varphi\left(x_{0}, a_{1}, \ldots, a_{n}\right)$ then there is an element $a_{0} \in M_{1} \cap M_{2}$ such that $\mathcal{M}_{i}=\varphi\left(a_{0}, a_{1}, \ldots, a_{n}\right), i=1,2$.

Theorem 3.2. Let $\mathcal{M}_{1}$ and $\mathcal{M}_{2}$ be elementary substructures of structure $\mathcal{M}$ in a language $\Sigma$. The following are equivalent:

(1) $\mathcal{M}\left(M_{1} \cup M_{2}\right) \prec \mathcal{M}$;

(2) for any formula $\varphi\left(x_{0}, x_{1}, \ldots, x_{n}\right)$ of the language $\Sigma$ and for any elements $a_{1}, \ldots, a_{n} \in M_{1} \cap M_{2}$ if $\mathcal{M} \models \exists x_{0} \varphi\left(x_{0}, a_{1}, \ldots, a_{n}\right)$ then there is an element $a_{0} \in M\left(M_{1} \cup M_{2}\right)$ such that $\mathcal{M}\left(M_{1} \cup M_{2}\right) \models \varphi\left(a_{0}, a_{1}, \ldots, a_{n}\right)$.

The following examples illustrate valuations of the conditions (2) in Theorems 3.1 and 3.2.

Example 3.3. Consider a structure $\mathcal{M}$ in a graph language $\left\{R^{(2)}\right\}$ with a symmetric irreflexive relation $R$ and elements $a_{1}, a_{2}, a_{3}, a_{4}$ such that

$$
R=\left\{\left[a_{1}, a_{3}\right],\left[a_{1}, a_{4}\right],\left[a_{2}, a_{3}\right],\left[a_{2}, a_{4}\right]\right\}
$$

The substructures $\mathcal{M}_{1} \subset \mathcal{M}$ and $\mathcal{M}_{2} \subset \mathcal{M}$ with the universes $\left\{a_{1}, a_{2}, a_{3}\right\}$ and $\left\{a_{1}, a_{2}, a_{4}\right\}$ respectively satisfy the formula $\varphi\left(a_{1}, a_{2}\right) \rightleftharpoons \exists x\left(R\left(a_{1}, x\right) \wedge R\left(a_{2}, x\right)\right)$ whereas $\mathcal{M}_{1} \cap \mathcal{M}_{2}$ does not satisfy that formula since appropriate elements for $x$ belong to $M_{1} \oplus M_{2}$.

Example 3.4. Consider a structure $\mathcal{M}$ of graph language $\left\{R^{(2)}\right\}$ with symmetric irreflexive relation $R$ and with elements $a_{1}, a_{2}, a_{3}$ such that $R=\left\{\left[a_{1}, a_{3}\right],\left[a_{2}, a_{3}\right]\right\}$. The substructures $\mathcal{M}_{1} \subset \mathcal{M}$ and $\mathcal{M}_{2} \subset \mathcal{M}$ with the universes $\left\{a_{1}\right\}$ and $\left\{a_{2}\right\}$ form the substructure $\mathcal{M}\left(M_{1} \cup M_{2}\right)$ with the universe $\left\{a_{1}, a_{2}\right\}$ and it does not satisfy the formula $\varphi\left(a_{1}, a_{2}\right)$ in Example 3.3. At the same time the structure $\mathcal{M}$ satisfies this formula.

Since in some cases elementary substructures of given structure $\mathcal{M}$ form the lattice with respect to the operations $\mathcal{M}_{1} \wedge \mathcal{M}_{2}=\mathcal{M}_{1} \cap \mathcal{M}_{2}$ and $\mathcal{M}_{1} \vee \mathcal{M}_{2}=\mathcal{M}\left(M_{1} \cup M_{2}\right)$, the study of hypergraphs $\mathcal{H}(\mathcal{M})$, for these cases, is reduced to study of the lattices $L(\mathcal{M})$. As Example in [13] shows, the lattices $L(\mathcal{M})$ can be nondistributive unlike the description in Theorem 2.6, where correspondent lattices are distributive, and for finite $H\left(\mathcal{M}_{0}\right)$ even form Boolean algebras.

In the given context hypergraphs/lattices with minimal, i.e. least structures play an important role. These structures can be obtained from an arbitrary structure by addition of constants interpreted by all elements of the structure. Besides, these minimal structures exist for finite sets $H(\mathcal{M})$.

In [27], the following theorem on dichotomy for minimal structures is proved.

Theorem 3.5. Let $\mathcal{M}_{0}$ be a minimal structure, $\mathcal{M}$ be its saturated elementary extension and $p \in S_{1}\left(\mathcal{M}_{0}\right)$ be unique non-algebraic 1-type. Then exactly one of the following conditions holds: 
(I) the structure $\left(p(M), \operatorname{Sem}_{p}\right)$ is a pregeometry, where $\mathrm{Sem}_{p}$ is the relation of semi-isolation on the set of realizations of the type $p$, i.e. the following conditions are satisfied:

(S1) Monotony: if $A \subseteq B$ then $A \subseteq \operatorname{Sem}_{p}(A) \subseteq \operatorname{Sem}_{p}(B)$;

(S2) Finite character: $\operatorname{Sem}_{p}(A)=\bigcup\left\{\operatorname{Sem}_{p}\left(A_{0}\right) \mid A_{0}\right.$ is a finite subset of $\left.A\right\}$;

(S3) Transitivity: $\operatorname{Sem}_{p}(A)=\operatorname{Sem}_{p}\left(\operatorname{Sem}_{p}(A)\right)$;

(S4) Exchange property (Symmetry): if $a \in \operatorname{Sem}_{p}(A \cup\{b\}) \backslash \operatorname{Sem}_{p}(A)$ then $b \in \operatorname{Sem}_{p}(A \cup\{a\})$;

(II) for some finite $A \subset M$ there exists an infinite set $C_{0} \subseteq \operatorname{dcl}\left(A \cup M_{0}\right)$ and a definable quasi-order $\leq$ on $\mathcal{M}$ such that $C_{0}$ orders a type over $A$ :

(D1) for any $c \in C_{0}$ the set $\left\{x \in C_{0} \mid c \leq x\right\}$ is a cofinite subset of $C_{0}$;

(D2) $C_{0}$ is an initial segment of $\mathcal{M}$ : if $c \in C_{0}$ and $m \leq c$, then $m \in C_{0}$.

Basic examples illustrating Theorem 3.5 are represented by ordered structures $\langle\omega,<\rangle$ and $\left\langle\omega+\omega^{*},<\right\rangle$. The conclusion of Theorem 2.6 holds for both structures. Moreover, for $\mathcal{M}_{1} \equiv\langle\omega,<\rangle$ and $\mathcal{M}_{2} \equiv\left\langle\omega+\omega^{*},<\right\rangle$ the structures $L\left(\mathcal{M}_{1}\right)$ and $L\left(\mathcal{M}_{2}\right)$ form atomic Boolean algebras, whose atoms are defined by equivalence classes, being closures of singletons, not in $\omega+\omega^{*}$, taking all predecessors and successors.

Return to Example 2.7. It is known that the intersection of convex sets is convex, whereas the intersection of dense orders can be not dense. For instance, any interval $[a, b]$ contains countable dense subsets $X, Y$ such that $X \cap Y=\{a, b\}$. It means that for the structure $\mathcal{M}^{\prime} \equiv\left\langle\mathbf{Q},<, c_{q}\right\rangle_{q \in \mathbf{Q}}$ the structure $L\left(\mathcal{M}^{\prime}\right)$ forms a lattice, moreover, a Boolean algebra, if and only if each type in $S_{1}\left(\operatorname{Th}\left(\mathcal{M}^{\prime}\right)\right)$ has at most one realization in $\mathcal{M}^{\prime}$. If $\mathcal{M}^{\prime}$, with the lattice $L\left(\mathcal{M}^{\prime}\right)$, realizes $\lambda$ non-principal 1-types, then $\left|L\left(\mathcal{M}^{\prime}\right)\right|=2^{\lambda}$. Thus, the following proposition holds.

Proposition 3.6. For the structure $L\left(\mathcal{M}^{\prime}\right)$ the following are equivalent:

(1) $L\left(\mathcal{M}^{\prime}\right)$ is a lattice;

(2) $L\left(\mathcal{M}^{\prime}\right)$ forms an atomic Boolean algebra;

(3) each type in $S_{1}\left(\operatorname{Th}\left(\mathcal{M}^{\prime}\right)\right)$ has at most one realization in $\mathcal{M}^{\prime}$, and if $\mathcal{M}^{\prime}$ realizes $\lambda$ non-principal 1 -types, then $\left|L\left(\mathcal{M}^{\prime}\right)\right|=2^{\lambda}$.

Proposition 3.6 admits natural modifications for a series of theories with minimal models, for instance, for models, obtained by replacement of elements in $\mathcal{M}^{\prime}$ with finite antichains of fixed cardinality marked by unary predicates $P_{q}$ instead of constants $c_{q}$. Note that admitting replacement of constants $c_{q}$ by infinite antichains $P_{q}$ the structure $L\left(\mathcal{M}^{\prime}\right)$ is not a lattice since $P_{q}$ can be divided by some elementary substructures $\mathcal{M}_{1}^{\prime}, \mathcal{M}_{2}^{\prime} \prec \mathcal{M}^{\prime}$ into two disjoint parts, whence $\mathcal{M}_{1}^{\prime} \cap \mathcal{M}_{2}^{\prime} \nprec \mathcal{M}^{\prime}$.

Clearly, as above, in the general case if there are separable elements in definable sets $A \subseteq M$ of structure $\mathcal{M}$ then $L(\mathcal{M})$ is not closed under intersections, i.e., $L(\mathcal{M})$ is not even a lower semilattice. Thus, the following proposition holds.

Proposition 3.7. If $L(\mathcal{M})$ is a lattice then $\mathcal{M}$ does not have definable sets $A \subseteq M$ containing elements separable each other, in particular, $\mathcal{M}$ does not contain $\mathcal{H}$-free sets $A \subseteq M$.

In view of Proposition 3.7 it is natural, for given structure $\mathcal{M}$, along with $L(\mathcal{M})$ to consider for sets $X \subseteq M$ the following relative structures $L_{X}(\mathcal{M})$. Denote by $H_{X}(\mathcal{M}$ the family of all sets in $H(\mathcal{M}$ containing the set $X$. Then $L_{X}(\mathcal{M}) \rightleftharpoons\left\langle H_{X}(\mathcal{M} ; \wedge, \vee\rangle\right.$, where for structures $\mathcal{M}_{1}, \mathcal{M}_{2} \prec \mathcal{M}$ containing $X, \mathcal{M}_{1} \wedge \mathcal{M}_{2}=\mathcal{M}_{1} \cap \mathcal{M}_{2}$ and $\mathcal{M}_{1} \vee \mathcal{M}_{2}=\mathcal{M}\left(M_{1} \cup M_{2}\right)$.

Note that if $X$ is a universe of some elementary substructure of structure $\mathcal{M}$ then definable sets $A \subseteq M$ already do not contain elements separable by sets in $L_{X}(\mathcal{M})$. Then, in any case, $\mathcal{M}_{1} \wedge \mathcal{M}_{2}$ is a substructure of $\mathcal{M}$ and the elementarity of that substructure is characterized by Theorem 3.1.

The following example illustrates that apart from the density there are other reasons preventing to consider $L(\mathcal{M})$ as a lattice.

Example 3.8 [28]. Let $\mathcal{M}=\left\langle M ;<, P^{1}, U^{2}, c_{i}\right\rangle_{i \in \omega}$ be a linearly ordered structure such that $\mathcal{M}$ is a disjoint union of interpretations of unary predicates $P$ and $\neg P$, where $\neg P(\mathcal{M})<P(\mathcal{M})$. We identify interpretations of $P$ and $\neg P$ with the set $\mathbb{Q}$ of rational numbers with the natural order.

The symbol $U$ interprets the binary relation defined as follows: for any $a \in P(\mathcal{M}), b \in \neg P(\mathcal{M}) U(a, b) \Leftrightarrow$ $\Leftrightarrow b<a+\sqrt{2}$

The constants $c_{i}$ interpret an infinite strictly increasing sequence on $P(\mathcal{M})$ as follows: $c_{i}=i \in \mathbb{Q}$.

Clearly that $T h(\mathcal{M})$ is a weakly o-minimal theory. Let

$$
\begin{gathered}
p(x):=\left\{x>c_{i} \mid i \in \omega\right\} \cup\{P(x)\} ; \\
q(y):=\left\{\forall t\left(U\left(c_{i}, t\right) \rightarrow t<y\right) \mid i \in \omega\right\} \cup\{\neg P(y)\} .
\end{gathered}
$$


Obviously, $p, q \in S_{1}(\emptyset)$ are nonisolated types and $p \not \perp^{w} q$. Since there are no $\emptyset$-definable bijections from $p\left(\mathcal{M}^{\prime}\right)$ onto $q\left(\mathcal{M}^{\prime}\right)$, where $\mathcal{M}^{\prime}$ is a model of $T h(\mathcal{M})$ realizing some of these types then $T h(\mathcal{M})$ is not quite o-minimal.

As shown in [28], $T h(\mathcal{M})$ has exactly 4 pairwise non-isomorphic countable models: the prime model $\mathcal{M}$, i.e., with $p(\mathcal{M})=\emptyset$ and $q(\mathcal{M})=\emptyset$; the model $\mathcal{M}_{1}$ such that $p\left(\mathcal{M}_{1}\right)$ has the ordering type $[0,1) \cap \mathbb{Q}, q\left(\mathcal{M}_{1}\right)$ has the ordering type $(0,1) \cap \mathbb{Q}$; the model $\mathcal{M}_{2}$ such that $p\left(M_{2}\right)$ has the ordering type $(0,1) \cap \mathbb{Q}, q\left(M_{2}\right)$ has the ordering type $[0,1) \cap \mathbb{Q}$; and the countable saturated model $\mathcal{M}_{3}$.

Therefore $\mathcal{M}_{1} \cap \mathcal{M}_{2} \nprec \mathcal{M}_{3}$. By this reason as well as by the possibility of violation of density in intersections, the structure $L\left(\mathcal{M}_{3}\right)$ does not form a lower semilattice.

Remark 3.9. Along with Example if we consider the known Ehrenfeucht's example with three models: a prime model $\mathcal{M}_{0}$, a weakly saturated model $\mathcal{M}_{1}$, and a countable saturated model $\mathcal{M}_{2}$, then the structure $L\left(\mathcal{M}_{2}\right)$ is not a lattice in view of presence of dense definable intervals but includes the three-element linearly ordered lattice consisting of the universes $M_{0}, M_{1}, M_{2}$.

\section{Lattice structures on sets of isomorphism types of models of a theory}

Following Example 3.8 and Remark 3.9 we consider a question on existence of natural lattices associated with hypergraphs $(M, H(\mathcal{M}))$ which a distinct to $L(\mathcal{M})$. Related lattices are lattices represented by RudinKeisler preorders RK $(T)$ [1] for isomorphism types of prime models of a theory $T$, over finite sets, or their lattice fragments.

The description [29] of structures $\operatorname{RK}(T)$ for Ehrenfeucht quite o-minimal theories $T$ implies that these structures, for the considered theories, form finite lattices $\operatorname{LRK}(T)$ consisting of $2^{k} \cdot 3^{s}$ elements and, in view of the main result of the paper [25], the number $I(T, \omega)$ of pairwise non-isomorphic countable models of $T$ equals $3^{k} \cdot 6^{s}, k, s \in \omega$.

The Hasse diagrams illustrating these lattices $\operatorname{LRK}(T)$ are represented in Figures 1-9 for the following values $k$ and $s$ :
1) $k=1, s=0$
2) $k=0, s=1$;
3) $k=2, s=0$;
4) $k=3, s=0$;
5) $k=0, s=2$;
6) $k=0, s=3$;
7) $k=1, s=1$;
8) $k=2, s=1$;
9) $k=1, s=2$.

Figure 1. $k=1, s=0$

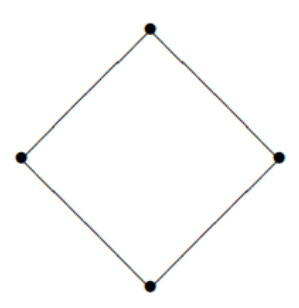

Figure 3. $k=2, s=0$
Figure 2. $k=0, s=1$

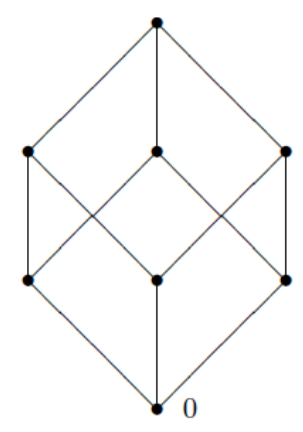

Figure 4. $k=3, s=0$ 
Theorem 4.1. Let $T$ be an Ehrenfeucht quite o-minimal theory, $I(T, \omega)=3^{k} \cdot 6^{s}, k, s \in \omega$. Then:

(1) $\operatorname{LRK}(T)$ is a lattice;

(2) $\operatorname{LRK}(T)$ is a Boolean algebra $\Leftrightarrow k \geq 1$ and $s=0$; in such a case the Boolean lattice $\operatorname{LRK}(T)$ has a cardinality $2^{k}$

(3) $\operatorname{LRK}(T)$ is linearly ordered $\Leftrightarrow k+s \leq 1$.

Proof. Let $\Gamma=\Gamma_{1} \cup \Gamma_{2}$ be a maximal independent set of nonisolated types in $S_{1}(T)$, where realizations of each type in $\Gamma_{1}$ generate three models, with prime one, and realizations of each type in $\Gamma_{2}$ generate six models, with prime one, $\left|\Gamma_{1}\right|=k,\left|\Gamma_{2}\right|=s$.

(1) We argue to show that $\operatorname{LRK}(T)$ is a lattice. Indeed, for isomorphism types $\widetilde{\mathcal{M}_{1}}$ and $\widetilde{\mathcal{M}_{2}}$ of prime model $\mathcal{M}_{1}$ and $\mathcal{M}_{2}$ over some finite sets $A$ and $B$, respectively, we define sets $X, Y \subseteq \Gamma \times\{0,1\}$ defining these isomorphism types such that $X=\left\{(p, 0)\left|\mathcal{M}_{1}\right|=p(a)\right.$ for some $a \in A$, and $\left|p\left(\mathcal{M}_{1}\right)\right|=1$ or $\left.p \in \Gamma_{1}\right\} \cup$ $\left\{(p, 1)\left|\mathcal{M}_{1}\right|=p(a)\right.$ for some $\left.a \in A,\left|p\left(\mathcal{M}_{1}\right)\right| \geq \omega, p \in \Gamma_{2}\right\} \quad$ and $Y=\left\{(q, 0) \mid \mathcal{M}_{2} \models q(b)\right.$ for some $b \in$ $B$, and $\left|q\left(\mathcal{M}_{2}\right)\right|=1$ or $\left.q \in \Gamma_{1}\right\} \cup\left\{(q, 1) \mid \mathcal{M}_{2} \models q(b)\right.$ for some $\left.b \in B,\left|q\left(\mathcal{M}_{2}\right)\right| \geq \omega, q \in \Gamma_{2}\right\}$. Then the isomorphism type for $\widetilde{\mathcal{M}_{1}} \wedge \widetilde{\mathcal{M}}_{2}$ corresponds to the set $U \subseteq \Gamma \times\{0,1\}$ consisting of all common pairs of $X$ and $Y$, as well as all possible pairs $(p, 0)$, if $(p, 0) \in X$ and $(p, 1) \in Y$, or $(p, 1) \in X$ and $(p, 0) \in Y$. And the isomorphism type for $\widetilde{\mathcal{M}_{1}} \vee \widetilde{\mathcal{M}_{2}}$ corresponds to the set $V \subseteq \Gamma \times\{0,1\}$ consisting of the following pairs:

i) all common pairs of $X$ and $Y$,

ii) all pairs $(p, i) \in X$ such that $Y \cap\{(p, 0),(p, 1)\} \emptyset$,

iii) all pairs $(p, i) \in Y$ such that $X \cap\{(p, 0),(p, 1)\} \emptyset$,

iv) all pairs $(p, 1)$ such that $(p, 0) \in X$ and $(p, 1) \in Y$, or $(p, 1) \in X$ and $(p, 0) \in Y$.

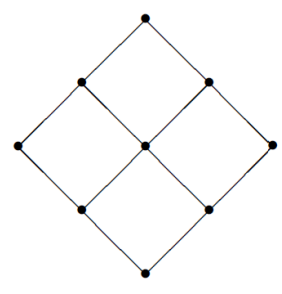

Figure $5 . k=0, s=2$

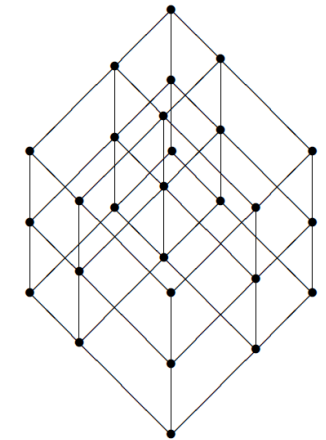

Figure $6 . k=0, s=3$

The defined correspondence witnesses that $\operatorname{LRK}(T)$ is a lattice.

(2) If $s \neq 0$ then $\operatorname{LRK}(T)$ is not a Boolean algebra by Stone Theorem, since the cardinality of each finite Boolean algebra equals $2^{n}$ for some $n \in \omega$ whereas $|\operatorname{LRK}(T)|=2^{k} \cdot 3^{s}$. If $s=0$ then $\operatorname{LRK}(T)$ is a Boolean algebra of a cardinality $2^{k}$ such that for isomorphism types $\widetilde{\mathcal{M}_{1}}$ and $\widetilde{\mathcal{M}_{2}}$ of prime models $\mathcal{M}_{1}$ and $\mathcal{M}_{2}$ over some finite sets $A$ and $B$, respectively, and for sets $X, Y \subseteq \Gamma$ such that $X=\left\{p(x) \in \Gamma \mid \mathcal{M}_{1} \models p(a)\right.$ for some $\left.a \in A\right\}$ and $Y=\left\{q(x) \in \Gamma\left|\mathcal{M}_{2}\right|=q(b)\right.$ for some $\left.b \in B\right\}$, the isomorphism type $\widetilde{\mathcal{M}_{1}} \wedge \widehat{\mathcal{M}_{2}}$ corresponds to the set $X \cap Y$, and the isomorphism type $\widetilde{\mathcal{M}_{1}} \vee \widetilde{\mathcal{M}_{2}}$ corresponds to the set $X \cup Y$.

(3) If $k+s \leq 1$ then $\operatorname{LRK}(T)$ is linearly ordered as shown in Figures 1 and 2 . If $k+s>1$ then $|\Gamma|>1$ and for distinct types $p, q \in \Gamma$ the isomorphism types of models $\mathcal{M}_{p}$ and $\mathcal{M}_{q}$ are incomparable in $\operatorname{LRK}(T)$.

The description for distributions of disjoint unions of Ehrenfeucht theories and the arguments for the proof of Theorem 4.1 allow to formulate the following theorem modifying Theorem 4.1.

Theorem 4.2. Let $T$ be a disjoint union of theories $T_{1}$ and $T_{2}$ in disjoint languages and having finite numbers $I\left(T_{1}, \omega\right)$ and $I\left(T_{2}, \omega\right)$ of countable models. Then:

(1) $\operatorname{LRK}(T)$ is a (Boolean) lattice $\Leftrightarrow \operatorname{LRK}\left(T_{1}\right)$ and $\operatorname{LRK}\left(T_{2}\right)$ are (Boolean) lattices;

(2) $\operatorname{LRK}(T)$ is linearly ordered $\Leftrightarrow \operatorname{LRK}\left(T_{1}\right)$ and $\operatorname{LRK}\left(T_{2}\right)$ are linearly ordered, and

$$
\min \left\{I\left(T_{1}, \omega\right), I\left(T_{2}, \omega\right)\right\}=1
$$

Proof. (1) If $\operatorname{LRK}(T)$ is a (Boolean) lattice, then $\operatorname{LRK}\left(T_{1}\right)$ and $\operatorname{LRK}\left(T_{2}\right)$ are (Boolean) lattices, since $\operatorname{LRK}\left(T_{1}\right)$ and $\operatorname{LRK}\left(T_{2}\right)$ are isomorphic to sublattices $L_{1}$ and $L_{2}$ of the lattice $\operatorname{LRK}(T)$, and elements/complements 
of elements in $\operatorname{LRK}(T)$ are represented as pairs of elements/complements of elements in $L_{1}$ and $L_{2}$. If $\operatorname{LRK}\left(T_{1}\right)$ and $\operatorname{LRK}\left(T_{2}\right)$ are (Boolean) lattices, then $\operatorname{LRK}(T)$ is a (Boolean) lattice again in view of aforesaid representation.

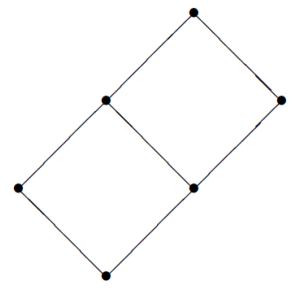

Figure 7. $k=1, s=1$

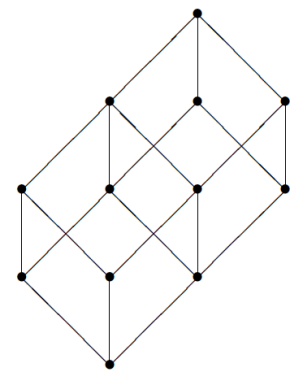

Figure 8. $k=2, s=1$

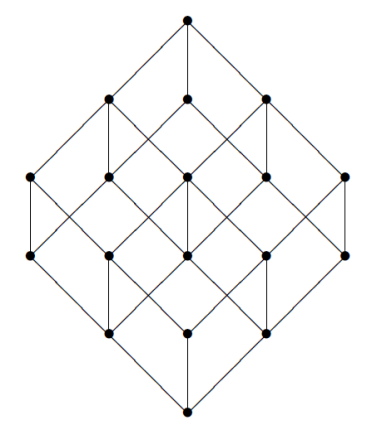

Figure 9. $k=1, s=2$

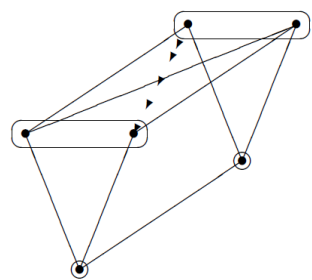

Figure 10. 6-Element diagram

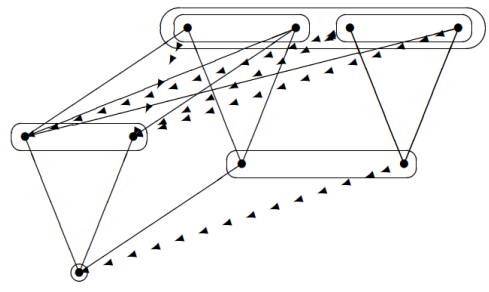

Figure 11. 9-Element diagram

(2) If $\operatorname{LRK}(T)$ is linearly ordered then $\operatorname{LRK}\left(T_{1}\right)$ and $\operatorname{LRK}\left(T_{2}\right)$ are linearly ordered, being isomorphic to substructures of $\operatorname{LRK}(T)$. Here $T_{1}$ or $T_{2}$ should be $\omega$-categorical, since otherwise prime models over pairs $\left(p_{1}, q_{1}\right)$ and $\left(p_{2}, q_{2}\right)$ occur LRK $(T)$-incomparable, where $p_{1}, p_{2} \in S_{1}\left(T_{1}\right), q_{1}, q_{2} \in S_{1}\left(T_{2}\right), p_{1}, q_{2}$ are isolated, $p_{2}, q_{1}$ are nonisolated.

If structures $\operatorname{LRK}\left(T_{1}\right)$ and $\operatorname{LRK}\left(T_{2}\right)$ linearly ordered, and $\min \left\{I\left(T_{1}, \omega\right), I\left(T_{2}, \omega\right)\right\}=1$, then $\operatorname{LRK}(T)$ is linearly ordered, since $\operatorname{LRK}(T) \simeq \operatorname{LRK}\left(T_{1}\right)$ for $I\left(T_{2}, \omega\right)=1$, and $\operatorname{LRK}(T) \simeq \operatorname{LRK}\left(T_{2}\right)$ for $I\left(T_{1}, \omega\right)=1$.

In Figures 10 and 11 we illustrate Theorem by structures $\operatorname{LRK}(T)$ in [30], for disjoint unions of theories, which are not lattices.

\section{Acknowledgements}

This research was partially supported by Committee of Science in Education and Science Ministry of the Republic of Kazakhstan (Grant No. AP05132546) and Russian Foundation for Basic Researches (Project No. 17-01-00531-a). 


\section{References}

1 Судоплатов С.В. Классификация счетных моделей полных теорий / С.В. Судоплатов. - Новосибирск: Изд-во НГТУ, 2018.

2 Судоплатов С.В. Об ациклических гиперграфах минимальных простых моделей / С.В. Судоплатов // Сиб. матем. журн. - 2001. - Т. 42. - № 6. - С. 1408-1412.

3 Судоплатов С.В. Гиперграфы простых моделей и распределения счётных моделей малых теорий // Фундаментальная и прикладная математика. - 2009. - Т. 15. - № 7. - С. 179-203.

4 Байкалова K.А. О некоторых гиперграфах простых моделей и порождаемых ими предельных моделях / К.А. Байкалова // Алгебра и теория моделей, 7. Сб. тр. / Под. ред. А.Г. Пинуса, К.Н. Пономарева, С.В. Судоплатова. - Новосибирск: Изд-во НГТУ, 2009. - С. 6-17.

5 Sudoplatov S.V. On the separability of elements and sets in hypergraphs of models of a theory / S.V. Sudoplatov // Вестн. Караганд. ун-та. Сер. Математика. - 2016. - Т. 82. - № 2. - С. 113-120.

6 Кулпешов Б.Ш. О гиперграфах простых моделей для вполне $о$-минимальных теорий с малым числом счетных моделей / Б.Ш. Кулпешов, С.В. Судоплатов // Ежегодная научная апрельская конференция Института математики и математического моделирования, посвящ. Дню науки, и научный семинар «Дифференциальные операторы и моделирование сложных систем» (DOMCS-2017), посвящ. 70-летнему юбилею проф. М.Т. Дженалиева, Алматы, 7-8 апр. 2017 г.: тез. докл. - Алматы: ИМММ, 2017. - С. 30-32.

7 Sudoplatov S.V. Derivative Structures in Model Theory and Group Theory / S.V. Sudoplatov // Akтуальные проблемы чистой и прикладной математики: Междунар. конф., посвящ. 100-летию со дня рождения академика Тайманова Асана Дабсовича, Алматы, 22-25 августа 2017 г.: тез. докл. Алматы: ИМММ, 2017. - С. 76-79.

8 Кулпешов Б.Ш. О декомпозиции гиперграфов моделей теории. Приложение к теориям унаров / Б.Ш. Кулпешов, С.В. Судоплатов // Синтаксис и семантика логических систем: Материалы 5-й Российской школы-семинара. - Улан-Удэ: Изд-во Бурят. госун-та, 2017. - С. 52-56.

9 Kulpeshov B.Sh. On relative separability in hypergraphs of models of theories / B.Sh. Kulpeshov, S.V. Sudoplatov. arXiv:1802.08088v1 [math.LO], 2018. - 11 p.

10 Paris J.B. On models of arithmetic / J.B. Paris // Conference in Mathematical Logic - London '70 (Bedford Coll., London, 1970). Lecture Notes in Math. - Vol. 255. - Berlin, 1972. - P. 251-280.

11 Gaifman H. Models and types of Peano's arithmetic / H. Gaifman // Annals of Mathematical Logic. 1976. - Vol. 9. - No. 3. - P. 223-306.

12 Paris J.B. Models of arithmetic and the 1-3-1 lattice / J.B. Paris // Fundamenta Mathematicae. - 1977. Vol. 95. - No. 3. - P. 195-199.

13 Wilkie A. On models of arithmetic having non-modular substructure lattices / A. Wilkie / Fundamenta Mathematicae. - 1977. - Vol. 95. - No. 3. - P. 223-237.

14 Schmerl J.H. Extending models of arithmetic / J.H. Schmerl // Annals of Mathematical Logic. - 1978. Vol. 14. - P. 89-109.

15 Mills G. Substructure lattices of models of arithmetic / G. Mills // Annals of Mathematical Logic. 1979. - Vol. 16. - No. 2. - P. 145-180.

16 Schmerl J.H. Finite substructure lattices of models of Peano arithmetic / J.H. Schmerl // Proc. Amer. Math. Soc. - 1993. - Vol. 117. - No. 3. - P. 833-838.

17 Schmerl J.H. Diversity in substructures / J.H. Schmerl. 361:145-161, Providence, RI, 2004.

18 Schmerl J.H. Substructure lattices and almost minimal end extensions of models of Peano arithmetic / J.H. Schmerl // Mathematical Logic Quarterly. - 2004. - Vol. 50. - No. 6. - P. 533-539.

19 Kossak R. The structure of models of Peano arithmetic / R. Kossak, J.H. Schmerl // Oxford Science Publications. Vol. 50. - Oxford: The Clarendon Press, Oxford University Press, 2006.

20 Schmerl J.H. Nondiversity in substructures / J.H. Schmerl // The Journal of Symbolic Logic. — 2008. Vol. 73. - No. 1. - P. 193-211.

21 Schmerl J.H. Infinite substructure lattices of models of Peano Arithmetic / J.H. Schmerl // J. Symbolic Logic. - 2010. - Vol. 75. - No. 4. - P. 1366-1382.

22 Abdul-Quader A. Interstructure Lattices and Types of Peano Arithmetic / A. Abdul-Quader // PhD. 
dissertation. - New-York: The City University of New York, 2017. - 78 p.

23 Baizhanov B.S. Expansion of a model of a weakly o-minimal theory by a family of unary predicates / B.S. Baizhanov // The Journal of Symbolic Logic. - 2001. - Vol. 66. - P. 1382-1414.

24 Кулпешов Б.Ш. Ранг выпуклости и ортогональность в слабо о-минимальных теориях / Б.Ш. Кулпешов // Известия НАН РК. Серия физико-математическая. - 2003. - Т. 227. - С. 26-31.

25 Kulpeshov B.Sh. Vaught's conjecture for quite o-minimal theories / B.Sh. Kulpeshov, S.V. Sudoplatov // Annals of Pure and Applied Logic. - 2017. - Vol. 168. - No. 1. - P. 129-149.

26 Macpherson H.D. Weakly o-minimal structures and real closed fields / H.D. Macpherson, D. Marker, C. Steinhorn // Transactions of The American Mathematical Society. - 2000. - Vol. 352. - P. 54355483.

27 Tanović P. Minimal first-order structures / P. Tanović // Annals of Pure and Applied Logic. - 2011. Vol. 162. - No. 11. - P. 948-957.

28 Alibek A. Examples of countable models of a weakly o-minimal theory/ A. Alibek, B.S. Baizhanov // International Journal of Mathematics and Physics. - 2012. - Vol. 3. - No. 2. - P. 1-8.

29 Kulpeshov B.Sh. Distributions of countable models of quite o-minimal Ehrenfeucht theories / B.Sh. Kulpeshov, S.V. Sudoplatov. arXiv:1802.08078v1 [math.LO], 2018. - 13 p.

30 Sudoplatov S.V. Distributions of countable models of disjoint unions of Ehrenfeucht theories / S.V. Sudoplatov. arXiv:1802.09364v1 [math.LO], 2018. - 12 p.

\title{
Б.Ш. Кулпешов, С.В. Судоплатов
}

\section{Теория модельдерінің гиперграфтарындағы құрылымдар туралы}

\begin{abstract}
Теория модельдерінің гиперграфиясы теорияларды, сонымен бірге графикалық объектілерді қоса, семантикалық объектілер туралы маңызды құрылымдық ақпаратты алуға мүмкіндік беретін объектілерге жатады. Осы мақалада құрылымдық, оның ішінде торлы, модельдік теорияның гиперграфтардың қасиеттері анықталып зерттелді. Теория үлгілерінің гиперграфты торын сипаттау, сондай-ақ теория түрлерінің изоморфизм түрлеріндегі құрылымдар берілген.
\end{abstract}

Kiлm сөздер: модельдер гиперграфы, элементарлық теория, элементарлық ішкі құрылымдық жиын, тор құрылымы.

\section{Б.Ш. Кулпешов, С.В. Судоплатов}

\section{О структурах в гиперграфах моделей теории}

Гиперграфы моделей теории относятся к производным объектам, позволяющим получать существенную структурную информацию как о самих теориях, так и о сопутствующих семантических объектах, включая графовые объекты. В статье определены и исследованы структурные, в том числе решеточные свойства гиперграфов моделей теории. Дана характеризация решеточности гиперграфов моделей теории, а также структур на множествах типов изоморфизма теории.

Ключевые слова: гиперграф моделей, элементарная теория, элементарно подструктурное множество, решеточная структура.

\section{References}

1 Sudoplatov, S.V. (2018). Klassifikatsiia shchetnykh modelei polnykh teorii [Classification of countable models of complete theories]. Novosibirsk: Izdatelstvo NHTU [in Russian]. 
2 Sudoplatov, S.V. (2001). Ob atsiklicheskikh hiperhrafakh minimalnykh prostykh modelei / S.V. Sudoplatov [On acyclic hypergraphs of minimal prime models]. Sibirskii matematicheskii zhurnal - Siberian Mathematical Journal, Vol. 42, 6, 1408-1412 [in Russian].

3 Sudoplatov, S.V. (2010). Hiperhrafy prostykh modelei i raspredeleniia schetnykh modelei malykh teorii [Hypergraphs of prime models and distributions of countable models of small theories]. Fundamentalnaia i prikladnaia matematika - J. Math. Sciences, Vol. 169, Issue 5, 680-695 [in Russian].

4 Baikalova, K.A. (2009). O nekotorykh hiperhrafakh prostykh modelei i porozhdaemykh imi predelnykh modeliakh [On some hypergraphs of prime models and limit models generated by them]. Alhebra $i$ teoriia modelei - Algebra and Model Theory, 7. A.G. Pinus, K.N. Ponomaryov, S.V. Sudoplatov (Eds.). Novosibirsk: Izdatelstvo NHTU [in Russian].

5 Sudoplatov, S.V. (2016). On the separability of elements and sets in hypergraphs of models of a theory. Vestnik Karahandinskoho universiteta. Seriia Matematika - Bulletin of Karagandy University. Series Mathematics, Vol. 82, Issue 2, 113-120.

6 Kulpeshov, B.Sh., \& Sudoplatov, S.V. (2017). O hiperhrafakh prostykh modelei dlia vpolne $o$-minimalnykh teorii s malym chislom schetnykh modelei [On hypergraphs of prime models for quite $o$-minimal theories with small number of countable models]. Proceedings from Differential operators and modelling complex systems: ezhehodnaia nauchnaia aprelskaia konferentsiia Instituta matematiki i matematicheskoho modelirovaniia, posviashch. Dniu nauki, i nauchnyi seminar (DOMCS-2017), posviashch. 70-letnemu iubil. prof. M.T. Dzhenalieva, Almaty (7-8 aprel, 2017 hoda) - Annual Scientific April Conference of Institute of Mathematics and Mathematical Modelling devoted to Science Day and Scientific Seminar (DOMCS-2017) devoted to 70-th anniversary of professor M.T. Dzhenaliev, Almaty Abstracts of talks, Almaty: IMMM, 30-32 [in Russian].

7 Sudoplatov, S.V. (2017). Derivative Structures in Model Theory and Group Theory. Proceedings from Actual Problems of Pure and Applied Mathematics: Mezhdunarodnaia konferentsiia posviashchennaia 100-letiiu so dnia rozhdeniia akademika Taimanova Asana Dabsovicha, Almaty (22-25 avhusta 2017 hoda) - International Conference devoted to 100-th anniversary of academician A.D. Taimanov, Almaty, 22-25 August 2017: Abstracts of talks, (pp. 76-79). Almaty: IMMM.

8 Kulpeshov, B.Sh., \& Sudoplatov, S.V. (2017). O dekompozitsii hiperhrafov modelei teorii. Prilozhenie k teoriiam unarov [On decomposition of hypergraphs of models of a theory. Appendix to theories of unars]. Syntax and Semantics of Logical Systems: 5-i Rossiiskoi shkoly-seminara - 5-th Russian School-Seminar. (pp. 52-56). Ulan-Ude: Izdatelstvo Buriatskoho hosuniversiteta [in Russian].

9 Kulpeshov, B.Sh., \& Sudoplatov, S.V. (2018). On relative separability in hypergraphs of models of theories, arXiv:1802.08088v1 [math.LO].

10 Paris, J.B. (1972). On models of arithmetic. Conference in Mathematical Logic - London 'ro (Bedford Coll., London, 1970). Lecture Notes in Math., Vol. 255, Berlin, 251-280.

11 Gaifman, H. (1976). Models and types of Peano's arithmetic. Annals of Mathematical Logic, Vol. 9, 3, 223-306.

12 Paris, J.B. (1977). Models of arithmetic and the 1-3-1 lattice. Fundamenta Mathematicae, Vol. 95, 3, 195-199.

13 Wilkie, A. (1977). On models of arithmetic having non-modular substructure lattices. Fundamenta Mathematicae, Vol. 95, 3, 223-237.

14 Schmerl, J.H. (1978). Extending models of arithmetic. Annals of Mathematical Logic, Vol. 14, 89-109.

15 Mills, G. (1979). Substructure lattices of models of arithmetic. Annals of Mathematical Logic, Vol. 16, 2, $145-180$.

16 Schmerl, J.H. (1993). Finite substructure lattices of models of Peano arithmetic Proc. Amer. Math. Soc., Vol. 117, 3, 833-838.

17 Schmerl, J.H. (2004). Diversity in substructures. 361:145-161. Providence, RI.

18 Schmerl, J.H. (2004). Substructure lattices and almost minimal end extensions of models of Peano arithmetic. Mathematical Logic Quarterly, Vol. 50, 6, 533-539.

19 Kossak, R., \& Schmerl, J.H. (2006). The structure of models of Peano arithmetic. Oxford Science Publications, Vol. 50. Oxford: The Clarendon Press, Oxford University Press.

20 Schmerl, J.H. (2008). Nondiversity in substructures. Journal Symbolic Logic, Vol. 73, 1, $193-211$. 
21 Schmerl, J.H. (2010). Infinite substructure lattices of models of Peano Arithmetic. The Journal of Symbolic Logic, Vol. 75, 4, 1366-1382.

22 Abdul-Quader, A. (2017). Interstructure Lattices and Types of Peano Arithmetic. Ph.D. dissertation. New-York: The City University of New York.

23 Baizhanov, B.S. (2001). Expansion of a model of a weakly o-minimal theory by a family of unary predicates. The Journal of Symbolic Logic, Vol. 66, 1382-1414.

24 Kulpeshov, B.Sh. (2003). Ranh vypuklosti i ortohonalnost v slabo o-minimalnykh teoriiakh [Vaught's conjecture for quite o-minimal theories]. Izvestiia NAN RK, seriia fiziko-matematicheskaia - Annals of Pure and Applied Logic, Vol. 168, 1, 129-149 [in Russian].

25 Kulpeshov, B.Sh., \& Sudoplatov, S.V. (2017). Convexity rank and orthogonality in weakly o-minimal theories. News of National Academy of Sciences of the Republic of Kazakhstan, series physics-mathematics, Vol. 227, 26-31.

26 Macpherson, H.D., Marker, D., \& Steinhorn, C. (2000). Weakly o-minimal structures and real closed fields. Transactions of The American Mathematical Society, Vol. 352, 5435-5483.

27 Tanović, P. (2011). Minimal first-order structures. Annals of Pure and Applied Logic, Vol. 162, 11, 948-957.

28 Alibek, A., \& Baizhanov, B.S. (2012). Examples of countable models of a weakly o-minimal theory. International Journal of Mathematics and Physics, Vol. 3, 2, 1-8.

29 Kulpeshov, B.Sh., \& Sudoplatov, S.V. (2018). Distributions of countable models of quite $o$-minimal Ehrenfeucht theories. arXiv:1802.08078v1 [math.LO].

30 Sudoplatov, S.V. (2018). Distributions of countable models of disjoint unions of Ehrenfeucht theories. arXiv:1802.09364v1 [math.LO]. 